\title{
A comparison of eating disorder symptomatology, psychological distress and psychosocial function between early, typical and later onset anorexia nervosa
}

\author{
Zoe M. Jenkins ${ }^{1,2^{*}}$ (D) Lior M. Chait ${ }^{1}$, Leonardo Cistullo ${ }^{1}$ and David J. Castle ${ }^{1,2}$
}

\begin{abstract}
Objective: Epidemiological studies suggest that the incidence of anorexia nervosa (AN) is increasing in younger populations, with some evidence that clinical differences occur according to age of onset (AOO), which may impact prognostic outcomes. The current study sought to compare eating disorder (ED) symptomatology, psychological distress and psychosocial function between early onset (EO), typical onset (TO) and later onset (LO) AN in a large sample of treatment-seeking patients with a diagnosis of AN.

Methods: Participants included 249 individuals with a diagnosis of AN who were assessed at an outpatient ED service. The sample was divided into three groups based on $\mathrm{AOO}$; those with an $\mathrm{AOO} \leq 14$ years $(N=58)$ were termed 'EO-AN', those with an AOO between 15 and 18 years $(N=113)$ were termed 'TO-AN' and those with an AOO of $>18$ years $(N=78)$ were termed 'LO-AN'. Comparisons were made between AOO groups on assessments of ED symptomatology, psychological distress and psychosocial function.

Results: EO-AN patients reported a significantly longer illness duration than both TO-AN and LO-AN groups. After controlling for effect of illness duration, the EO-AN group demonstrated significantly higher ED symptomatology and dysmorphic concern compared to the LO-AN group. The EO-AN group demonstrated significantly decreased cognitive flexibility compared to both the TO-AN and LO-AN groups.

Discussion: These findings suggest that clinical differences do occur according to AOO in AN whereby EO-AN may represent a more severe form of illness that is not attributable to increased illness duration. Treatment strategies which specifically address patients with EO-AN may improve long term health outcomes and recovery.
\end{abstract}

Keywords: Anorexia nervosa, Age of onset, Eating disorders, Depression, Anxiety, Stress, Psychosocial

\section{Plain English summary}

Presentations of anorexia nervosa (AN) are increasing in young populations. There is some evidence that there are differences in clinical features according to age of onset. The current study compared individuals with

\footnotetext{
* Correspondence: zoe.jenkins@svha.org.au

${ }^{1}$ Mental Health Service, St. Vincent's Hospital, Melbourne, Australia

2Department of Psychiatry, University of Melbourne, Melbourne, Australia
}

early, typical and later onset AN on eating disorder (ED) symptoms, psychological distress and psychosocial function in a large sample of treatment-seeking patients. Individuals with an early onset AN demonstrated a longer illness duration, higher ED symptoms and dysmorphic concern than those with later onset AN. Moreover, individuals with early onset AN demonstrated decreased cognitive flexibility compared to both typical onset and later onset AN. Treatment strategies for individuals with

(c) The Author(s). 2020 Open Access This article is licensed under a Creative Commons Attribution 4.0 International License, which permits use, sharing, adaptation, distribution and reproduction in any medium or format, as long as you give appropriate credit to the original author(s) and the source, provide a link to the Creative Commons licence, and indicate if changes were made. The images or other third party material in this article are included in the article's Creative Commons licence, unless indicated otherwise in a credit line to the material. If material is not included in the article's Creative Commons licence and your intended use is not permitted by statutory regulation or exceeds the permitted use, you will need to obtain permission directly from the copyright holder. To view a copy of this licence, visit http://creativecommons.org/licenses/by/4.0/ The Creative Commons Public Domain Dedication waiver (http://creativecommons.org/publicdomain/zero/1.0/) applies to the data made available in this article, unless otherwise stated in a credit line to the data. 
early onset AN should incorporate environmental and developmental factors that may contribute to the development and maintenance of AN.

\section{Introduction}

Anorexia nervosa (AN) is a severe illness that has an approximate lifetime prevalence of $1.7 \%$ [1], is associated with significant psychiatric comorbidity [2], and demonstrates the highest mortality rate of any psychiatric disorder [3]. The c is between 15 and 19 years old [4] and while population-based studies suggest that the overall incidence of AN in the general population has remained static since the 1970's [5, 6], there has been a proportional increase in childhood presentations (aged below 14 years) $[7,8]$ and a trend for individuals presenting with $\mathrm{AN}$ at a younger age $[9,10]$ over the past two decades. AOO has been demonstrated as a clinically significant feature in various psychiatric illnesses including affective disorders [11, 12], psychotic disorders [13] and anxiety disorders $[14,15]$ and may have important prognostic implications [16]. Accordingly, exploration of clinical features across AOO may allow demarcation of symptom presentation and inform treatment prognosis.

Previous investigations into AOO in AN are inconclusive, with conflicting evidence surrounding the impact of AOO on ED severity, prognostic implications and psychological profile. Evidence for increased ED severity and poorer prognostic outcomes in EO-AN (as compared to LO-AN) have been demonstrated including; more rapid weight loss $[17,18]$, poorer long-term outcomes of low body weight and psychiatric comorbidity [19], and a longer duration of illness [20]. However, other studies have found no difference in severity of weight loss between EO- and LO-AN [21], fewer cases of extremely low weight in those with EO-AN compared to LO-AN [22], and a positive association between low body mass index (BMI) and increased AOO [23]. Assessments of the impact of AOO on psychological profile in individuals with AN also provide contrasting evidence. Whereas one study reported better self-esteem in those with EO-AN [24], others have reported that individuals with EO-AN demonstrate higher maturity fear, impulsivity and asceticism (interpreted as greater character fragility) than those with LO-AN [25].

A contributing factor to the discordant evidence to date may be the lack of consensus for what age constitutes 'EO' and 'LO' AN. EO-AN has previously been depicted as an AOO of $<14$ years in some studies [22, 24, 26], < 16 years [25] and $<25$ years in others [21], while others still have used puberty and menarche to demarcate AOO groups [27].

To date, there is a paucity of studies that compare levels of psychological distress, such as depression and anxiety and psychosocial functioning across different AOO groups in AN. Moreover, the majority of investigations into $\mathrm{AOO}$ in ED populations have utilised inpatient samples or retrospective healthcare records, with fewer investigations into outcomes in community and out-patient ED groups.

The current study aims to compare clinical presentation across three AOO groups in individuals with a diagnosis of AN in a large sample of treatment-seeking adults at an out-patient ED service. Specifically, measures of ED symptomatology, psychological distress and psychosocial function will be compared across those with an EO-AN, typical-onset AN (TO-AN) and LO-AN groups. It is anticipated that those with EO-AN will exhibit increased ED symptomatology, psychological distress and more impaired psychosocial functioning than those with either TO-AN or LO-AN.

\section{Methods}

\section{Participants and procedure}

Data from all patients with a diagnosis of AN $(n=249)$ who were assessed for treatment at the Body Image and Eating Disorders Recovery Service (BETRS) at St. Vincent's Hospital, Melbourne Australia between 2012 and 2019 were included in this study. The service provided at BETRS includes outpatient and day patient programs and is described elsewhere [28]. Diagnosis of AN was determined through a comprehensive assessment by specialist clinicians under the guidance of consultant psychiatrists in accordance with DSM-5 [29]. Data were collected upon initial presentation as part of a larger assessment protocol. The study was granted ethics approval from the Human Research Ethics Committee at St Vincent's Hospital, Melbourne and all procedures were in line with the Declaration of Helsinki. Informed consent was obtained from all participants.

\section{Measures}

Demographic and clinical information:

- Information relating to ethnicity, education, employment status and partnered status.

- Age of illness onset was self-reported by patients at initial assessment.

- The duration of illness was calculated as the duration from self-reported AOO until age at initial assessment.

Eating disorder symptomatology:

- BMI: Height and weight were assessed using calibrated instruments. The participant's BMI was calculated by dividing their weight $(\mathrm{kg})$ by the square of their height $(\mathrm{m})$.

- The Eating Disorder Examination Questionnaire (EDE-Q) [30] is a 28-item self-report measure of psychological domains relevant to individuals with 
eating disorders. The questionnaire asks individuals to report on items in relation to the past 28 days and provides subscales of eating restraint, eating concern, weight concern, shape concern and global score, with higher scores on the EDE-Q indicate greater levels of disordered eating.

- Dysmorphic Concern: The Dysmorphic Concern Questionnaire (DCQ) is an assessment of levels of dysmorphic concern [31] and has gained support as a brief screening measure for BDD [32]. It is a selfreport questionnaire that has 7 items rated on a 4point Likert scale from $0=$ "Not at all" to $3=$ "Much more than most people".

- AN subtype: During the assessment process and evaluation of ED diagnosis, clinicians at BETRS reported the AN subtype as either 'restraint' or 'binge-purge' as per DSM-5 criteria [29].

Psychological distress and psychosocial assessment:

- The Depression Anxiety Stress Scale (DASS-21) [33] is a 21-item self-report instrument designed to measure the three related negative emotional states of depression, anxiety and tension/stress over the past week. Individual subscale scores representing depression, anxiety and stress were used here.

- Self-efficacy: The General Self-Efficacy Scale (GSES) provides a measure of optimistic sense of personal competence [34].

- Cognitive flexibility: The Cognitive Flexibility Scale (CFS) measures a person's awareness of communication alternatives, willingness to adapt to challenging situations and self-efficacy in being flexible [35].

- Quality of Life: The Quality of Life Enjoyment and Satisfaction Questionnaire Short Form (Q-LES-Q$\mathrm{SF}$ ) is a 16-item self-report measure of QoL [36]. Responses are scored on a 5-point Likert scale, with higher scores indicating greater enjoyment and satisfaction with life. The Q-LES-Q-SF measures enjoyment and satisfaction with overall well-being including physical health, mood, social and occupation functioning, relationships and daily functioning. The overall Q-LES-Q-SF score was used here.

- Disability: The Brief Disability Questionnaire (BDQ) is an assessment of overall perceived physical and mental disability [37].

\section{Statistical analyses}

Given the lack of official criterion to classify EO- and LO$\mathrm{AN}$, we grouped the participants into three groups; EO-AN (AOO $\leq 14$ years), TO-AN (AOO between 15 and 18 years) and LO-AN (AOO of above 18 years), as has been done previously [20, 24]. See Supplementary Material Table 3. and 4. for additional analyses using a median split.
Data analysis was performed using SPSS (IBM, SPSS Statistics Version 25). Means and standard deviations were calculated for continuous variables, and frequencies were measured for categorical variables. Given the crosssectional design of the assessments, total frequencies that were collected for each measure are stated. For individuals with multiple assessments, only their first assessment data was used.

Between-group differences on continuous demographic variables were assessed using multiple one-way ANOVAs with Tukey post hoc analysis. Length of illness duration was used as a covariate measure in a series of ANCOVA analyses to determine the differences between AOO groups on measures of ED symptomatology, psychological distress and psychosocial function. Post hoc analysis was performed with a Bonferroni adjustment. Between-group comparisons of categorical variables were conducted using chi-squared tests of association; Fisher's exact test was used to analyse categorical variables where cell counts were low $(n<5)$. For all analyses, significance was set at $p<0.05$. Missing values were excluded on a list wise basis.

\section{Results}

The mean age of the sample $(N=249,94.4 \% \mathrm{~F})$ was $27.04 \pm 9.44$ years at the time of assessment, of which $23.3 \%(n=58)$ had an AOO of $\leq 14,45.4 \%(n=113)$ had an AOO between 15 and 18 years and $31.3 \%(n=78)$ had an AOO of over 18. Participant characteristics and comparison between AOO groups are presented in Table 1.

Individuals with EO-AN were significantly younger at assessment than those with LO-AN and had a significantly younger $\mathrm{AOO}$ and longer duration of illness than those with TO-AN or LO-AN. The comparison of ED symptomatology, psychological distress and psychosocial functioning between the three AOO groups (after adjustment for illness duration) are presented in Table 2.

The EO-AN group demonstrated significantly higher levels of ED symptoms in subscales of eating concern, shape concern, weight concern and global score of the EDE-Q, compared to the LO-AN group. The EO-AN group also reported significantly higher levels of dysmorphic concern than the LO-AN group. Individuals with EO-AN had significantly lower scores of cognitive flexibility, compared to the TO-AN and LO-AN groups. There were no significant differences between groups on other variables.

\section{Discussion}

The current study utilised a large sample of treatmentseeking adults at an out-patient ED service to investigate ED symptomatology, psychological distress and psychosocial function between EO-AN, TO-AN and LO-AN patients. Our hypotheses that those with EO-AN would 
Table 1 Participant characteristics

\begin{tabular}{|c|c|c|c|c|}
\hline \multirow[t]{2}{*}{ Measure } & \multirow{2}{*}{$\begin{array}{l}\text { EO-AN } \\
M \pm S D \text { or } N(\%) \\
N=58\end{array}$} & \multirow{2}{*}{$\begin{array}{l}\text { TO-AN } \\
M \pm \text { SD or } N(\%) \\
N=113\end{array}$} & \multirow{2}{*}{$\begin{array}{l}\text { LO-AN } \\
M \pm \text { SD or } N(\%) \\
N=78\end{array}$} & \multirow[t]{2}{*}{$\begin{array}{l}p \text { - } \\
\text { value }\end{array}$} \\
\hline & & & & \\
\hline Age & $24.77 \pm 7.94$ & $24.96 \pm 8.48$ & $30.59 \pm 10.06^{* *}$ & $<.001$ \\
\hline Age of onset & $12.31 \pm 2.35$ & $16.19 \pm 1.03^{* *}$ & $24.01 \pm 6.83^{* *}$ & $<.001$ \\
\hline Duration of illness & $12.46 \pm 8.94$ & $8.08 \pm 8.44^{*}$ & $6.39 \pm 7.87^{* *}$ & $<.001$ \\
\hline Gender & & & & 0.832 \\
\hline Male & $3(5.2 \%)$ & $5(4.4 \%)$ & $5(6.4 \%)$ & \\
\hline Female & $55(94.8 \%)$ & $108(95.6 \%)$ & $73(93.6 \%)$ & \\
\hline Ethnicity & & & & 0.769 \\
\hline Caucasian & $48(82.8 \%)$ & $89(78.8 \%)$ & $57(73.1 \%)$ & \\
\hline Other European & $3(5.2 \%)$ & $5(4.4 \%)$ & $6(7.7 \%)$ & \\
\hline East Asian & $2(3.4 \%)$ & $4(3.5 \%)$ & $1(1.3 \%)$ & \\
\hline Aboriginal and Torres Strait Islander & $1(1.7 \%)$ & $2(1.8 \%)$ & $2(2.6 \%)$ & \\
\hline Other/Unknown & $4(6.9 \%)$ & $13(11.5 \%)$ & $12(15.4 \%)$ & \\
\hline Education & & & & 0.177 \\
\hline Secondary School & $24(41.4 \%)$ & $35(31.0 \%)$ & $16(20.5 \%)$ & \\
\hline Tertiary commenced/completed & $30(51.7 \%)$ & $68(60.2 \%)$ & $50(64.1 \%)$ & \\
\hline Vocational & $1(1.7 \%)$ & $3(2.7 \%)$ & $2(2.6 \%)$ & \\
\hline Other/Unknown & $3(5.2 \%)$ & $7(6.2 \%)$ & $10(12.8 \%)$ & \\
\hline Employment & & & & 0.226 \\
\hline Student & $19(32.8 \%$ & $48(42.5 \%)$ & $18(23.1 \%)$ & \\
\hline Full-time employed & $4(6.9 \%)$ & $7(6.2 \%)$ & $9(11.5 \%)$ & \\
\hline Part-time employed & $11(19.0 \%)$ & $23(20.4 \%)$ & $13(16.7 \%)$ & \\
\hline Home duties & $1(1.7 \%)$ & $3(2.7 \%)$ & $4(5.1 \%)$ & \\
\hline Unemployed & $4(6.9 \%)$ & $9(8.0 \%)$ & $7(9.0 \%)$ & \\
\hline Unable to work because of illness & $17(29.3 \%)$ & $17(15.0 \%)$ & $23(29.5 \%)$ & \\
\hline Unknown/missing & $2(3.4 \%)$ & $6(5.3 \%)$ & $4(5.1 \%)$ & \\
\hline Marital status & & & & 0.180 \\
\hline Never married & $46(79.3 \%)$ & $88(77.9 \%)$ & $53(67.9 \%)$ & \\
\hline Widowed & - & - & $1(1.3 \%)$ & \\
\hline Divorced/separated & $1(1.7 \%)$ & $4(3.5 \%)$ & $8(10.3 \%)$ & \\
\hline Married/defacto & $8(13.8 \%)$ & $10(8.8 \%)$ & $11(14.1 \%)$ & \\
\hline Unknown/missing & $3(5.2 \%)$ & $11(9.7 \%)$ & $5(6.4 \%)$ & \\
\hline
\end{tabular}

*compared to EO-AN, $p<.01 ;{ }^{* *}$ compared to EO-AN, $p<.001$

EO-AN early onset anorexia nervosa; TO-AN typical onset anorexia nervosa; $L O-A N$ later onset anorexia nervosa

demonstrate increased ED symptomatology, psychological distress and more impaired psychosocial function than those with TO-AN or LO-AN were partly supported. There were no differences in BMI or AN subtype between the three groups. However, the EO-AN group reported a significantly longer illness duration than both TO-AN and LO-AN groups. After controlling for the impact of illness duration, the EO-AN group reported significantly increased ED symptomatology and dysmorphic concern than those with LO-AN. Moreover, the EO-AN group demonstrated significantly decreased cognitive flexibility as compared to both the TO-AN and
LO-AN groups. There were no differences between groups on psychological distress or other psychosocial outcomes.

In accordance with prior research, our observations that patients with EO-AN reported a longer illness duration, higher ED symptomatology and dysmorphic concern than those with LO-AN, which indicates that EO-AN may present with a more severe form of illness [25,38]. The increased severity in ED symptomatology demonstrated by the EO-AN group was consistent across all domains of the EDE-Q aside from restraint, which demonstrated a trend towards being increased in the EO-AN group. This 
Table 2 Comparison of ED severity, psychological distress and psychosocial function across AOO groups

\begin{tabular}{|c|c|c|c|c|}
\hline \multirow[t]{2}{*}{ Measure } & $\begin{array}{l}\mathrm{EO}-\mathrm{AN} \\
\mathrm{M} \pm \mathrm{SD} \text { or } \mathrm{N}(\%)\end{array}$ & $\begin{array}{l}\text { TO-AN } \\
M \pm S D \text { or } N(\%)\end{array}$ & $\begin{array}{l}\text { LO-AN } \\
M \pm S D \text { or } N(\%)\end{array}$ & $\begin{array}{l}p \text {-value, effect } \\
\text { size }\left(\eta^{2}\right)\end{array}$ \\
\hline & $N=58$ & $N=113$ & $N=78$ & \\
\hline & $n=54$ & $n=107$ & $n=75$ & \\
\hline \multirow[t]{2}{*}{ BMl } & $17.07 \pm 2.25$ & $16.74 \pm 2.27$ & $16.75 \pm 2.99$ & $p=.463, \eta 2=.007$ \\
\hline & $n=50$ & $n=82$ & $n=65$ & \\
\hline AN Subtype & & & & 0.744 \\
\hline Restraint & 45 & 75 & 61 & \\
\hline \multirow[t]{2}{*}{ Binge-purge } & 5 & 7 & 4 & \\
\hline & $n=49$ & $n=85$ & $n=64$ & \\
\hline \multicolumn{5}{|l|}{ EDE-Q } \\
\hline Restraint & $4.68 \pm 1.37$ & $3.88 \pm 1.67$ & $3.75 \pm 1.82$ & $p=.060, \eta 2=.030$ \\
\hline Eating concern & $4.28 \pm 1.00$ & $3.92 \pm 1.36$ & $3.44 \pm 1.63^{*}$ & $p=.031, \eta 2=.037$ \\
\hline Shape concern & $5.26 \pm 1.06$ & $4.80 \pm 1.22$ & $4.29 \pm 1.50^{* *}$ & $p=.004, \eta 2=.057$ \\
\hline Weight concern & $4.91 \pm 1.33$ & $4.51 \pm 1.38$ & $3.92 \pm 1.57^{*}$ & $p=.019, \eta 2=.042$ \\
\hline \multirow[t]{2}{*}{ Global } & $4.68 \pm 1.21$ & $4.18 \pm 1.37$ & $3.74 \pm 1.54^{*}$ & $p=.030, \eta 2=.036$ \\
\hline & $n=21$ & $n=40$ & $n=32$ & \\
\hline \multirow[t]{2}{*}{ Dysmorphic concern } & $13.33 \pm 4.16$ & $11.63 \pm 4.87$ & $10 \pm 5.51^{*}$ & $p=.029, \eta 2=.077$ \\
\hline & $n=55$ & $n=103$ & $n=74$ & \\
\hline \multicolumn{5}{|l|}{ DASS-21 } \\
\hline Depression & $28.76 \pm 11.92$ & $24.41 \pm 11.76$ & $22.81 \pm 13.11$ & $p=.087, \eta 2=.022$ \\
\hline Anxiety & $22.18 \pm 11.01$ & $18.52 \pm 11.77$ & $16.30 \pm 10.85$ & $p=.051, \eta 2=.026$ \\
\hline \multirow[t]{2}{*}{ Stress } & $28.55 \pm 9.00$ & $24.84 \pm 10.02$ & $23.46 \pm 10.95$ & $p=.116, \eta 2=.019$ \\
\hline & $n=20$ & $n=41$ & $n=32$ & \\
\hline \multirow[t]{2}{*}{ Cognitive flexibility } & $40.85 \pm 7.84$ & $46.71 \pm 7.76^{*}$ & $48.84 \pm 8.67^{* *}$ & $p=.006, \eta 2=.110$ \\
\hline & $n=18$ & $n=39$ & $n=31$ & \\
\hline \multirow[t]{2}{*}{ Self-efficacy } & $23.33 \pm 5.53$ & $24.72 \pm 5.38$ & $26.42 \pm 5.58$ & $p=.210, \eta 2=.037$ \\
\hline & $n=45$ & $n=81$ & $n=63$ & \\
\hline \multirow[t]{2}{*}{ Quality of life } & $34.07 \pm 10.17$ & $37.28 \pm 10.05$ & $37.16 \pm 10.72$ & $p=.530, \eta 2=.007$ \\
\hline & $n=57$ & $n=106$ & $n=74$ & \\
\hline Disability & $12.65 \pm 5.86$ & $10.68 \pm 5.07$ & $10.69 \pm 5.68$ & $p=.117, \eta 2=.019$ \\
\hline
\end{tabular}

*compared to EO-AN, $p<.05 ;{ }^{* *}$ compared to EO-AN, $p<.005$

EO-AN Early onset anorexia nervosa; TO-AN Typical onset anorexia nervosa; LO-AN Later onset anorexia nervosa; BMI Body mass index; EDE-Q Eating disorder examination questionnaire; DASS-21 Depression anxiety stress scale

supports previous findings of more severe ED behaviours, such as complete refusal of oral intake and more severe restriction, in patients with EO-AN. Similarly, distorted self-perception of body image, a key feature of AN [29, 39], was significantly higher in those with EO-AN compared to LO-AN, consistent with previous findings [25]. Contributing factors to the increased ED psychopathology seen in the EOAN group may include various biological and environmental factors, which differ across development. These include pressures experienced by younger patients, such as changes related to puberty and increased susceptibility to external negative influences on body image perception and idealisation [40]. It has been postulated that onset of AN prior to puberty may intensify perceived body image ideals [41], whereby the associated increase in adipose tissue and widening of the hips in adolescent females during puberty may exacerbate cognitions related to thin body ideal [18]. Moreover, experience of body change in the EO-AN group may also be substantially influenced by social media ideals, peer relationships and the emergence of gender roles [42, 43]. The importance of physical attractiveness and the consolidation of sexuality have been demonstrated to influence self-concept and psychological profile at this stage of development [44]. Moreover, rates of teasing and bullying have been demonstrated to be higher in EO-AN than LO-AN [21], supportive of the theory that early developmental trauma may contribute to increased levels of psychological distress as well as enduring patterns of body image disturbance $[45,46]$. 
Another feature that is widely associated with AN is cognitive inflexibility $[47,48]$, which involves deficits in the ability to adapt thinking or attention to shifting goals or environmental stimuli [49]. The current study demonstrated significantly lower levels of cognitive flexibility in patients with EO-AN compared to both TO-AN and LO-AN, supportive of previous findings of lower metacognitive abilities in patients with EO-AN [50]. Decreased cognitive flexibility, as demonstrated in the EOAN group, may manifest in heightened rigidity in thinking and be reflected in more severe ED cognitions [51], resulting in behaviours such as categorisation of food and calorie counting [52]. Moreover, cognitive inflexibility may also lead to problems in finding solutions to managing difficulties and distress, therefore maintaining maladaptive thoughts and behaviours in AN [52], contributing to the challenges faced in psychotherapeutic interventions in this patient group. Specifically, diminished cognitive flexibility may be a limiting factor in cognitive behaviour therapy interventions, whereby a lack of communication of alternatives may lead to poor engagement with treatment and suboptimal outcomes of therapy. Indeed, cognitive inflexibility and obsessional thinking have been shown to predate the onset of $\mathrm{AN}$, persist over the course of the illness and contribute to later relapses in adulthood $[53,54]$.

Investigations into psychological distress in the current study found no significant differences between the three AOO groups in measures of depression, anxiety and stress. However, there was a trend for increased anxiety in individuals with EO-AN compared to TO-AN and LO$\mathrm{AN}$, which may be due to the abovementioned developmental and environmental influences experienced by this group of patients. It has also been suggested that EO-AN is under stronger influence of biological processes such as pre-illness alterations in neural circuits [55], which may lead to higher expression of distress and anxiety symptoms. Psychological distress was universally high across all three groups, which is representative of the established high rates of comorbid anxiety and depressive disorders across varying AOO groups in $\mathrm{AN}[24,38,56,57]$.

\section{Conclusion}

The current study builds upon previous research and has demonstrated that a large community-based treatment-seeking sample of patients with EO-AN exhibit more severe ED pathology and higher dysmorphic concern, compared with LO-AN patients, which are not attributable to a longer illness duration. Moreover, individuals with EO-AN demonstrated decreased cognitive flexibility compared to those with TO-AN or LO-AN. The disparities between AOO groups have potential implications for prognostic and treatment outcomes. Indeed, knowledge of increased ED severity and decreased cognitive flexibility may enable clinicians to adopt more tailored interventions for this vulnerable group. Further investigation into understanding the early developmental influences on illness manifestation could highlight unique targets of future interventions.

The limitations of the current study include the crosssectional nature of assessments, with not all outcomes completed by the participants and a lack of long-term follow up. Other limitations include the inclusion of selfreported AOO, measures of ED symptomatology and psychological distress. Future research should investigate the long-term implications of AOO on treatment outcomes. This will enable informed early detection and intervention with $\mathrm{EO}$ patients as well as targeted interventions.

\section{Supplementary information}

Supplementary information accompanies this paper at https://doi.org/10. 1186/s40337-020-00337-w.

Additional file 1. Results from a data-driven approach (median split) to dichotomise the sample into two AOO groups.

\section{Abbreviations}

AN: Anorexia nervosa; EO: Early onset; TO: Typical onset; LO: Later onset; ED: Eating disorder; AOO: Age of onset; BMI: Body mass index; BETRS: Body image and eating disorders recovery service; DSM-5: Diagnostic and statistical manual of mental disorders, 5th edition; EDE-Q: Eating disorder examination questionnaire; DCQ: Dysmorphic concern questionnaire; DASS-

21: Depression anxiety stress scale; GSES: General self-efficacy scale;

CFS: Cognitive flexibility scale; Q-LES-Q-SF: Quality of life enjoyment and satisfaction questionnaire short form; BDQ: Brief disability questionnaire; SPSS: Statistical package for the social sciences

\section{Acknowledgements}

The authors would like to thank the participants involved and members of the Body Image and Eating Disorders Recovery Service (BETRS) Research and Evaluation Group (REG) for their contribution.

\section{Authors' contributions}

All authors designed the project. ZMJ, LMC and LC drafted the manuscript. ZJ conducted the data analysis. All authors reviewed the final manuscript. The author (s) read and approved the final manuscript.

\section{Funding}

Not applicable.

\section{Availability of data and materials}

The datasets used and/or analysed during the current study are available from the corresponding author on reasonable request.

\section{Ethics approval and consent to participate}

The study was granted ethics approval from the Human Research Ethics Committee at St Vincent's Hospital, Melbourne and all procedures were in line with the Declaration of Helsinki. Informed consent was obtained from all participants.

\section{Consent for publication}

Not applicable.

\section{Competing interests}

DJC has received grant monies for research from Eli Lilly, Janssen Cilag, Roche, Allergen, Bristol-Myers Squibb, Pfizer, Lundbeck, Astra Zeneca, Hospira; Travel Support and Honoraria for Talks and Consultancy from Eli Lilly, BristolMyers Squibb, Astra Zeneca, Lundbeck, Janssen Cilag,Pfizer, Organon, SanofiAventis, Wyeth, Hospira, Servier, Seqirus; and is a current Advisory Board 
Member for Lu AA21004: Lundbeck; Varenicline: Pfizer; Asenapine: Lundbeck; Aripiprazole LAl: Lundbeck; Lisdexamfetamine: Shire; Lurasidone: Servier; Brexpiprazole: Lundbeck; Treatment Resistant Depression: LivaNova. He is founder of the Optimal Health Program, currently operating as Optimal Wellness. He is on the boards of both Mind Medicine Australia and The Mental health Foundation of Australia. He does not knowingly have stocks or shares in any pharmaceutical company. No other authors report any conflicts of interest.

Received: 21 May 2020 Accepted: 7 October 2020

Published online: 04 November 2020

\section{References}

1. Smink FR, van Hoeken D, Oldehinkel AJ, Hoek HW. Prevalence and severity of DSM-5 eating disorders in a community cohort of adolescents. Int J Eat Disord. 2014;47(6):610-9.

2. Bühren K, Schwarte R, Fluck F, Timmesfeld N, Krei M, Egberts K, et al. Comorbid psychiatric disorders in female adolescents with first-onset anorexia nervosa. Eur Eat Disord Rev. 2014;22(1):39-44.

3. Arcelus J, Mitchell AJ, Wales J, Nielsen S. Mortality rates in patients with anorexia nervosa and other eating disorders: a meta-analysis of 36 studies. Arch Gen Psychiatry. 2011;68(7):724-31.

4. Hoek HW, Van Hoeken D. Review of the prevalence and incidence of eating disorders. Int J Eat Disord. 2003;34(4):383-96.

5. Currin L, Schmidt U, Treasure J, Jick H. Time trends in eating disorder incidence. Br J Psychiatry. 2005;186(2):132-5.

6. Hoek HW. Incidence, prevalence and mortality of anorexia nervosa and other eating disorders. Curr Opin Psychiatry. 2006;19(4):389-94.

7. Nicholls DE, Lynn R, Viner RM. Childhood eating disorders: British national surveillance study. Br J Psychiatry. 2011;198(4):295-301.

8. Holland J, Hall N, Yeates DG, Goldacre M. Trends in hospital admission rates for anorexia nervosa in Oxford (1968-2011) and England (1990-2011): database studies. J R Soc Med. 2016;109(2):59-66.

9. van Son GE, van Hoeken D, Bartelds AIM, van Furth EF, Hoek HW. Time trends in the incidence of eating disorders: a primary care study in the Netherlands. Int J Eat Disord. 2006;39(7):565-9.

10. Favaro A, Caregaro L, Tenconi E, Bosello R, Santonastaso P. Time trends in age at onset of anorexia nervosa and bulimia nervosa. J Clin Psychiatry. 2009;70(12):1715-21.

11. Zisook S, Lesser I, Stewart JW, Wisniewski SR, Balasubramani G, Fava M, et al. Effect of age at onset on the course of major depressive disorder. Am J Psychiatr. 2007;164(10):1539-46.

12. Suominen $K$, Mantere $O$, Valtonen $H$, Arvilommi $P$, Leppämäki $S$, Paunio T, et al. Early age at onset of bipolar disorder is associated with more severe clinical features but delayed treatment seeking. Bipolar Disord. 2007;9(7):698-705.

13. Rajji T, Ismail Z, Mulsant B. Age at onset and cognition in schizophrenia: meta-analysis. Br J Psychiatry. 2009;195(4):286-93.

14. GBd M, Fontenelle LF, Versiani M. Early-onset social anxiety disorder in adults: clinical and therapeutic features. Braz J Psychiatry. 2005;27(1):32-6.

15. Millet B, Kochman F, Gallarda T, Krebs M, Demonfaucon F, Barrot I, et al. Phenomenological and comorbid features associated in obsessive-compulsive disorder: influence of age of onset. J Affect Disord. 2004;79(1-3):241-6.

16. Kessler RC, Amminger GP, Aguilar-Gaxiola S, Alonso J, Lee S, Ustun TB. Age of onset of mental disorders: a review of recent literature. Curr Opin Psychiatry. 2007;20(4):359.

17. Diamanti A, Bizzarri C, Gambarara M, Calce A, Montecchi F, Cappa M, et al. Bone mineral density in adolescent girls with early onset of anorexia nervosa. Clin Nutr. 2007;26(3):329-34.

18. Walker T, Watson HJ, Leach DJ, McCormack J, Tobias K, Hamilton MJ, et al. Comparative study of children and adolescents referred for eating disorder treatment at a specialist tertiary setting. Int J Eat Disord. 2014;47(1):47-53.

19. Herpertz-Dahlmann B, Dempfle A, Egberts KM, Kappel V, Konrad K, Vloet JA, et al. Outcome of childhood anorexia nervosa-the results of a five-to tenyear follow-up study. Int J Eat Disord. 2018;51(4):295-304.

20. Neubauer K, Weigel A, Daubmann A, Wendt H, Rossi M, Löwe B, et al. Paths to first treatment and duration of untreated illness in anorexia nervosa: are there differences according to age of onset? Eur Eat Disord Rev. 2014;22(4):292-8.

21. Shian Ming T, Kah Foo VK, Zainal KA, Hui YL. Late-vs. early-onset anorexia nervosa in Asia: Nosological, aetiological, and therapeutic implications. Int J Ment Health. 2017;46(3):227-42.
22. Matsumoto H, Takei N, Kawai M, Saito F, Kachi K, Ohashi Y, et al. Differences of symptoms and standardized weight index between patients with early-onset and late-onset anorexia nervosa. Acta Psychiatr Scand. 2001;104(1):66-71.

23. Kimura $\mathrm{H}$, Tonoike T, Muroya T, Yoshida K, Ozaki N. Age of onset has limited association with body mass index at time of presentation for anorexia nervosa: comparison of peak-onset and late-onset anorexia nervosa groups. Psychiatry Clin Neurosci. 2007;61(6):646-50.

24. Van Noort BM, Lohmar SK, Pfeiffer E, Lehmkuhl U, Winter SM, Kappel V. Clinical characteristics of early onset anorexia nervosa. Eur Eat Disord Rev. 2018;26(5):519-25.

25. Abbate-Daga G, Pierò A, Rigardetto R, Gandione M, Gramaglia C, Fassino S. Clinical, psychological and personality features related to age of onset of anorexia nervosa. Psychopathology. 2007;40(4):261-8.

26. Lask B, Bryant-Waugh R, Wright F, Campbell M, Willoughby K, Waller G. Family physician consultation patterns indicate high risk for early-onset anorexia nervosa. Int J Eat Disord. 2005;38(3):269-72.

27. Swenne I, Thurfjell B. Clinical onset and diagnosis of eating disorders in premenarcheal girls is preceded by inadequate weight gain and growth retardation. Acta Paediatr. 2003;92(10):1133-7.

28. Newton J, Bosanac P, Mancuso S, Castle D. Bridging the gap: does a specialist eating disorder service, aimed at developing a continuum of community care, make a difference? Australas Psychiatry. 2013;21(4):365-70.

29. American Psychiatric Association. Diagnostic and statistical manual of mental disorders (DSM-5 ${ }^{\oplus}$ ). American Psychiatric Pub; 2013.

30. Fairburn CG, Beglin SJ. Assessment of eating disorders: interview or selfreport questionnaire? Int J Eat Disord. 1994;16(4):363-70.

31. Oosthuizen P, Lambert T, Castle DJ. Dysmorphic concern: prevalence and associations with clinical variables. Aust N Z J Psychiatry. 1998;32(1):129-32.

32. Mancuso SG, Knoesen NP, Castle DJ. The Dysmorphic concern questionnaire: a screening measure for body Dysmorphic disorder. Aust N Z J Psychiatry. 2010;44(6):535-42.

33. Lovibond SH, Lovibond PF. Manual for the depression anxiety stress scales: Psychology Foundation of Australia; 1996.

34. Scholz U, Doña BG, Sud S, Schwarzer R. Is general self-efficacy a universal construct? Psychometric findings from 25 countries. Eur J Psychol Assess. 2002;18(3):242.

35. Martin MM, Rubin RB. A new measure of cognitive flexibility. Psychol Rep. 1995;76(2):623-6.

36. Endicott J, Nee J, Harrison W, Blumenthal R. Quality of life enjoyment and satisfaction questionnaire: a new measure. Psychopharmacol Bull. 1993;29(2): 321-6.

37. Von Korff M, Ustun TB, Ormel J, Kaplan I, Simon GE. Self-report disability in an international primary care study of psychological illness. J Clin Epidemiol. 1996;49(3):297-303.

38. Bueno B, Krug I, Bulik C, Jiménez-Murcia S, Granero R, Thornton L, et al. Late onset eating disorders in Spain: clinical characteristics and therapeutic implications. J Clin Psychol. 2014;70(1):1-17.

39. Hrabosky JI, Cash TF, Veale D, Neziroglu F, Soll EA, Garner DM, et al. Multidimensional body image comparisons among patients with eating disorders, body dysmorphic disorder, and clinical controls: a multisite study. Body Image. 2009;6(3):155-63.

40. Forman M, Davis WN. Characteristics of middle-aged women in inpatient treatment for eating disorders. Eat Disord. 2005;13(3):231-43.

41. Beilharz F, Phillipou A, Castle D, Jenkins Z, Cistullo L, Rossell S. Dysmorphic concern in anorexia nervosa: implications for recovery. Psychiatry Res. 2019; 273:657-61

42. Levine MP, Smolak L, Moodey AF, Shuman MD, Hessen LD. Normative developmental challenges and dieting and eating disturbances in middle school girls. Int J Eat Disord. 1994;15(1):11-20.

43. Smolak L, Striegel-Moore R. The implications of developmental research for eating disorders. The developmental psychopathology of eating disorders: Implications for research, prevention, and treatment. 1996:183-203.

44. Paxton SJ, Norris M, Wertheim EH, Durkin SJ, Anderson J. Body dissatisfaction, dating, and importance of thinness to attractiveness in adolescent girls. Sex Roles. 2005;53(9-10):663-75.

45. Bakalar JL, Shank LM, Vannucci A, Radin RM, Tanofsky-Kraff M. Recent advances in developmental and risk factor research on eating disorders. Curr Psychiatry Rep. 2015;17(6):42.

46. Gander M, Sevecke K, Buchheim A. Eating disorders in adolescence: attachment issues from a developmental perspective. Front Psychol. 2015;6:1136. 
47. Tchanturia K, Anderluh MB, Morris RG, Rabe-Hesketh S, Collier DA, Sanchez $P$, et al. Cognitive flexibility in anorexia nervosa and bulimia nervosa. J Int Neuropsychol Soc. 2004;10(4):513-20.

48. Abbate-Daga G, Buzzichelli S, Amianto F, Rocca G, Marzola E, McClintock $S M$, et al. Cognitive flexibility in verbal and nonverbal domains and decision making in anorexia nervosa patients: a pilot study. BMC Psychiatry. 2011; 11(1):162.

49. Dajani DR, Uddin LQ. Demystifying cognitive flexibility: implications for clinical and developmental neuroscience. Trends Neurosci. 2015;38(9):571-8.

50. Bravender T, Bryant-Waugh R, Herzog D, Katzman D, Kreipe R, Lask B, et al. Workgroup for classification of eating disorders in children and adolescents. Classification of child and adolescent eating disturbances. Int J Eat Disord. 2007:40(Suppl):S117-S22

51. Fassino S, Pieró A, Daga GA, Leombruni P, Mortara P, Rovera GG. Attentional biases and frontal functioning in anorexia nervosa. Int J Eat Disord. 2002; 31(3):274-83.

52. Aloi M, Rania M, Caroleo M, Bruni A, Palmieri A, Cauteruccio MA, et al. Decision making, central coherence and set-shifting: a comparison between binge eating disorder, anorexia nervosa and healthy controls. BMC Psychiatry. 2015;15(1):6

53. Thornton C, Russell J. Obsessive compulsive comorbidity in the dieting disorders. Int J Eat Disord. 1997;21 (1):83-7.

54. Green MW, Elliman NA, Wakeling A, Rogers PJ. Cognitive functioning, weight change and therapy in anorexia nervosa. J Psychiatr Res. 1996;30(5): 401-10

55. DeSocio JE. The neurobiology of risk and pre-emptive interventions for anorexia nervosa. J Child Adolesc Psychiatr Nurs. 2013;26(1):16-22.

56. Peebles R, Wilson JL, Lock JD. How do children with eating disorders differ from adolescents with eating disorders at initial evaluation? I Adolesc Health. 2006;39(6):800-5.

57. Cumella EJ, Kally Z. Profile of 50 women with midlife-onset eating disorders. Eat Disord. 2008;16(3):193-203.

\section{Publisher's Note}

Springer Nature remains neutral with regard to jurisdictional claims in published maps and institutional affiliations.

Ready to submit your research? Choose BMC and benefit from:

- fast, convenient online submission

- thorough peer review by experienced researchers in your field

- rapid publication on acceptance

- support for research data, including large and complex data types

- gold Open Access which fosters wider collaboration and increased citations

- maximum visibility for your research: over $100 \mathrm{M}$ website views per year

At $\mathrm{BMC}$, research is always in progress.

Learn more biomedcentral.com/submissions 